\title{
Инфографика еженедельника «Аргументы и факты»: медиаэстетический потенциал
}

\author{
Симакова С.И. \\ Челябинский государственный университет \\ Россия, 454001, Челябинск, ул. Братьев Кашириных, 129 \\ simakovi@mail.ru
}

\begin{abstract}
Аннотация. Тенденции глобализации, визуализации, панмедиатизации и развитие цифровых технологий обусловили формирование новых типов медиатекста, одной из важнейших характеристик которых стало эстетическое воздействие на адресата. Ученые обсуждают проблемы формирования новой медиаэстетики. Вместе с тем исследования, посвященные медиаэстетическому потенциалу инфографики, в российском исследовательском сегменте отсутствуют. В связи с этим автором предпринята попытка определить медиэстетический потенциал инфографик. Использованы методы сплошной выборки, кейс-стади и контент-анализа. Эмпирической базой исследования послужили журналистские материалы издания «Аргументы и факты» за 2018 год. Анализ инфографических публикаций позволил выделить их особенности: диалогический характер публицистического образа; сочетание политематичности инфографики и общих принципов представления информации; социальную направленность; влияние контекста на восприятие инфографики; нетипичность и необязательность интерактивности как свойства инфографики. На основе анализа публикаций издания «Аргументы и факты» выделены основные принципы представления информации и создания публицистического образа в поликодовом тексте, определены функции вербальных и визуальных средств, описан медиаэстетический потенциал инфографики. Результаты исследования могут быть использованы в учебном процессе и в научной деятельности при подготовке студентов и аспирантов медианаправлений.
\end{abstract}

Ключевые слова: визуализация, визуальные средства, медиаэстетика, поликодовый текст, эстетика медиа.

Благодарности: работа выполнена при поддержке Российского научного фонда, проект № 18-1800007 «Медиаэстетический компонент современной коммуникации».

Для цитирования: Симакова С.И. 2020. Инфографика еженедельника «Аргументы и факты»: медиаэстетический потенциал. Вопросы журналистики, педагогики, языкознания, 39 (3): 367-377. DOI 10.18413/2712-7451-2020-39-3-367-377

\section{Infographic of the weekly "Arguments and facts": media aesthetic potential}

\author{
Svetlana I. Simakova \\ Chelyabinsk State University, \\ 129 Kashirin Brothers St, Chelyabinsk, Russia, 454001 \\ simakovi@mail.ru
}

\begin{abstract}
The trends of globalization, visualization, panmediatization and the development of digital technologies have led to the formation of new types of media text, one of the most important characteristics of which is the aesthetic impact on the addressee. Scientists today are discussing the problems of the formation of new media aesthetics. At the same time, there are no studies on the mediaaesthetic potential of infographics in the Russian research segment. In this regard, the author made an attempt to determine the media-aesthetic potential of infographics. Methods of continuous sampling, case
\end{abstract}


studies and content analysis were used. The empirical basis of the study was the journalistic materials of the Argumenty i Fakty publication for 2018. The analysis of infographic publications made it possible to highlight their features: the dialogical nature of the journalistic image; combination of polythematicity of infographics and general principles of information presentation; social orientation; the influence of context on the perception of infographics; atypical and optional interactivity as properties of infographics. Based on the analysis of the publications of the publication "Arguments and Facts", the main principles of presenting information and creating a publicistic image in a polycode text are highlighted, the functions of verbal and visual means are determined, the media aesthetic potential of infographics is described. This is the novelty of the presented study. Its results can be used in the educational process and in scientific activity in the preparation of students and postgraduates in media fields.

Keywords: visualization, visual media, media aesthetics, multicode text, media aesthetics.

Acknowledgements: this work was supported from the Russian Science Foundation, project No. 18-1800007 "Media-aesthetic component of modern communication".

For citation: Simakova S.I. 2020. Infographic of the weekly "Arguments and facts": media aesthetic potential. Issues in Journalism, Education, Linguistics, 39 (3): 367-377 (in Russian). DOI 10.18413/2712-7451-2020-39-3-367-377

\section{Введение}

Внимание современных ученых к медиатексту обусловлено трансформацией всей системы массовой коммуникации, что особенно заметно отразилось на способах представления информации журналистами, которые оказались в условиях жесткой конкуренции и потеряли монополию на новость: «Происходящие ныне трансформационные процессы в журналистике и медиасистемах вновь заставляют обратиться к осмыслению сущности журналистской деятельности и происходящих в ней радикальных перемен, которые актуализируют научные дискуссии, особенно учитывая рост претензий к журналистам и массмедиа» [Короченский, 2019, с. 7]. С другой стороны, журналисты сегодня активно осваивают новые технологии, позволяющие изменять принципы взаимоотношений с адресатом и постоянно предлагать аудитории новые, интересные и разнообразные, текстовые медиаформаты. Сложился совершенно иной взгляд на информацию, когда, как объясняет Н. Луман, информация становится «событием, которое меняет состояние системы» [Luhmann, 1987, p. 102], меняет картину мира. Соответственно, трансформируется и предназначенный для массмедиа текст, и способы его предъявления и восприятия-потребления.

На форму и содержание публикации в СМИ сегодня влияют сформировавшиеся тенденции и цифровые технологии. К тенденциям, влияющим на формирование новых типов медиатекста, в том числе и инфографику, следует отнести следующие: панмедиатизация, визуализация, усиление роли контекста, доминирование поликодовых публикаций в СМИ, а, следовательно, усиление роли эстетической составляющей в медиакоммуникации. Все эти тенденции проявляются в первую очередь в языке - способах, приемах, средствах представления информации, поэтому и возникает необходимость говорить о медиаэстетике [См.: Manovich, 2001; Krotz, 2007; Mitchell, 2015; Загидуллина, 2017a, б; Topchii, 2018; Загидуллина, 2019; Торchii, 2019].

Важнейшая при изучении инфографики тенденция - это визуализация, которая сегодня рассматривается разными учеными [Mirzoeff, 1998; Cairo, 2013; Симакова и др., 2017; Simakova, Topchii, 2018; Simakova et al., 2019 и др.]. Инфографику можно оценивать как одно из наиболее ярких проявлений этой тенденции, когда авторы медиатекста находят наиболее эффективный способ представления («упаковки») больших данных, то есть такое представление информации, которое помогает адресанту быть лаконичным и убедительным, а адресату с интересом и без особых усилий воспринимать довольно большой объем информации. И в случае удачного взаимодействия журналиста и дизайнера полу- 
чать и эстетическое удовольствие от данного вида медиатекста, так как оформление оказывается не менее значимым компонентом, чем содержание [Выровцева, Симакова, 2019]. Это усиливает и роль контекста при восприятии инфографики.

Контекстное восприятие в условиях «глобальной деревни» (М. Маклюэн) разрушает устоявшиеся границы и правила, трансформируя норму и предлагая при встрече с каждым новым адресатом новый вариант прочтения уже опубликованного авторского высказывания. Развитие медиаязыка, который сегодня характеризуется взаимодействием разных знаковых систем, обусловлено его потенциальными возможностями находить необходимые средства для представления, отражения, интерпретации непрерывно усложняющейся реальной действительности, то есть событий, явлений, процессов, мнений и т. п. Интерактивность позволяет тиражировать субъективно оцениваемые факты до бесконечности, однако успех и эффективность коммуникации всегда зависит от понимания и приятия правил и знания средств (де)кодирования информации, представленной в инфографике с помощью разных знаковых систем: «...диалог должен оставаться декодируемым. Журналист создает систему символов, которые в совокупности дают этому определенное направление. Читатель должен понять, что стоит за содержанием. А для этого сам журналист должен понять, какой читатель стоит перед ним» [Левшаков, 2017, с. 130]. Сегодня не менее актуальны вопросы о том, насколько востребованы и каким образом воспринимаются заложенные адресантом смыслы, если потоки информации привели к усталости от нее и активному сопротивлению транслируемой новости; насколько уже сформировалась медиаэстетика - принципы восприятия новых поликодовых публикаций.

М.В. Загидуллина рассматривает медиаэстетику «как значимое условие коммуникации»: «Развитие web-технологий вело к облегчению пользования самыми разными инструментами, позволяющими создавать уникальные поликодовые медиа-объекты, совмещающие разные типы контента (визуально-образного, визуально-текстового, аудиального). < ..> При этом особый интерес для исследователей представляют несколько аспектов: социально-институциональный (вытеснение профессионалов любителями); социально-креативный (массовизация творческих технологий); социально-психологический (специфика массового творчества в клиповой культуре)» [Загидуллина, 2017б, с. 102]. Инфографика как поликодовый текст представляет сложную систему, в которой элементы разных знаковых систем образуют единое «визуальное, структурное, смысловое и функциональное целое, нацеленное на комплексное воздействие на адресата» [Ворошилова, 2006, с. 186]. В то же время поликодовость формирует и новые эстетические отношения в процессе коммуникации, и речь идет именно о медиаэстетике, в которой доминирует «эргономика взаимодействия сознания пользователя и контента $<\ldots>$, но главное - интерфейс, обеспечивающий это взаимодействие и ограничивающий его (“софт”, который и “правит бал”, по Мановичу)» [Загидуллина, 2019, c. 151].

Создатели современной инфографики учитывают все эти особенности массовой коммуникации, что проявляется в дизайнерских решениях, определяющих особенности восприятия поликодового медиатекста.

Таким образом, рассматривая теоретическую базу исследования, мы отмечаем, что вопросам визуализации журналистского материала, вопросам эстетики и медиаэстетики журналистики посвящено немало исследований. Однако исследований, посвященных медиаэстетическому потенциалу инфографики, в российской научной литературе нами обнаружено не было. Вместе с тем следует отметить, что в более ранних наших работах мы так или иначе рассматривали отдельные стороны этого вопроса. Можно считать, что данная работа, цель которой - рассмотреть медиаэстетический потенциал инфографики на примере инфографических публикаций «АиФ», является обобщеннием наших предыдущих наблюдений. 


\section{Объект и методы исследования}

В качестве объекта исследования была выбрана инфографика одного из самых популярных, о чем свидетельствуют тиражи и посещаемость сайта, издания - еженедельника «Аргументы и факты» (АиФ). Как один из наиболее узнаваемых брендов, «АиФ» позволяет проследить особенности развития медиаязыка, в частности, исследовать особенности функционирования инфографики в условиях развития указанных выше тенденций. Как массовое издание, которое «сохраняет миллионные тиражи, не превращаясь при этом в бульварное издание, ${ }^{1}$ «Аргументы и факты» становятся вполне репрезентативным объектом исследования и с точки зрения формирования медиаэстетики, а точнее - реализации в инфографике медиаэстетического потенциала поликодового медиатекста. Исследование основано на анализе инфографики юбилейного для «АиФ» 2018-го года - еженедельник отмечал 40 лет со дня основания.

На основе метода сплошной выборки была сформирована база инфографического контента издания - 388 единиц. Содержательный анализ медиатекстов, включающий метод кейс-стади и элементы контент-анализа, позволил выделить общие приемы и принципы представления разнотематической информации, при восприятии которой особое значение имеют элементы оформления, способы объединения вербальных, визуальных, иконических, мультимедийных компонентов.

\section{Результаты и их обсуждение (экспериментальная часть)}

В условиях «визуализированной медиакультуры» (П. Чубарь) инфографика представляет собой «динамично развивающийся инструмент визуализации. <...> Инфографика как продукт совместного творчества дизайнера и журналиста является “ценной социальной валютой”, эстетически привлекательной, информационно емкой, аттрактивной» [Симакова, 2020, с. 129]. Для массового издания «Аргументы и факты», стремящегося реагировать на постоянно возрастающие запросы своей - реальной и потенциальной - аудитории (перегруженной информацией, избалованной развлекательными форматами и альтернативными источниками) и в то же время сохранять традиции качественной журналистики, социальная направленность и общественная ценность публикаций остается одним из важнейших критериев мастерства, одной из обязательных традиций. С этой точки зрения особенно актуальным представляется исследование того, как эти ценности и традиции влияют на приемы и средства создания инфографики.

На основе анализа инфографических публикаций «АиФ» были выделены такие их особенности:

1) диалогический характер публицистического образа в инфографике «АиФ» проявляется как на уровне вербальных элементов, так и в инструментах дизайна;

2) политематичность инфографики «АиФ» не исключает общих принципов представления информации;

3) социальная направленность инфографики «АиФ» реализуется уже на уровне жанрового оформления - очень часто это советы, рекомендации, инструкции, актуальная справочная информация;

4) на восприятие инфографики влияет контекст: непосредственный, создаваемый соседними публикациями в еженедельнике (такой принято называть паратекстом) и общекультурный (исторический, национальный, эстетический);

5) интерактивность нельзя назвать типичным и обязательным свойством инфографики «АиФ» - из 388 публикаций интерактивных только 8, остальные представляют собой статичный тип публикации.

1 Здесь и далее: Издательский дом «Аргументы и факты». Электронное периодическое издание. URL: http://corp.aif.ru/page/4, (дата доступа: 20.06.2020) 
Остановимся на этих характеристиках подробнее.

Диалогичность - принципиальное свойство журналистского (публицистического) текста, так как, во-первых, он рассчитан на восприятие и ответную реакцию реципиента, а во-вторых, всегда является диалогом автора с миром, с адресатом, с самим собой (Л.Е. Кройчик). В инфографике «АиФ» диалогичность выражена уже на уровне заголовка, который очень часто имеет форму вопроса: «Кто имеет право на бесплатные социальные услуги?» (https://aif.ru/money/mymoney/socuslugi_dlya_bezzashchitnyh_komu_polozheny _i _kak_poluchit), «B каких странах так платят?» (https://aif.ru/money/economy /dengi_prosto_tak_mogut_li_u_nas_poyavitsya_bezuslovnye_vyplaty_grazhdanam), «На что обратить внимание при выборе ювелирных украшений?» (https://aif.ru/dontknows /infographics/kak_vybirat_yuvelirnye_izdeliya_infografika), «Как изменятся тарифы ЖКХ в 2018 году?» (https://aif.ru/money/mymoney/kak_v_rossii_izmenyatsya_tarify_na_zhkh _infografika), «Какие бывают виды нефтепродуктов?» https://aif.ru/money/economy/kakie _byvayut_vidy_nefteproduktov_infografika), «Какие блюда русской кухни помогут от похмелья?» (https://aif.ru/dontknows/infographics/kakie_blyuda_russkoy_kuhni_pomogut_ot_ pohmelya), «Сыграем в ящик? Как смотреть телевизор без вреда для здоровья» (https://aif.ru/health/life/sygraem_v_yashchik_kak_smotret_televizor_bez_vreda_dlya_zdorovya) -и др. Авторы инфографики отвечают на потенциальные вопросы адресата, что обусловлено ориентированностью еженедельника на общественно значимые проблемы: «Фактор адресата (Н.Д. Арутюнова) проявляется в удовлетворении информационных запросов и приведении композиционно-тематических и стилистических свойств текста в соответствие с вариантами гипотез об информационных ожиданиях читателя» [Дускаева, 2016, с. 29].

Другое востребованное средство диалогичности на вербальном уровне - это побудительные конструкции: «Не спите под телевизор. Не ешьте под телевизор. Не включайте телевизор на полную громкость» (https://aif.ru/health/life/sygraem_v_yashchik_kak_smotret _televizor_bez_vreda_dlya_zdorovya), «Когда деньги пришли, заказывайте шлагбаум...» (https://aif.ru/auto/roads/shlagbaum_ot_ponaehavshih_zakryt_dvor_ot_chuzhakov_stanet_prosh che), «Избегайте металлических конструкций. Выключите электроприборы...» (https://aif.ru/society/safety/kak_vesti_sebya_v_grozu_infografika) и т.п.

На визуальном уровне диалогичность, важнейшее качество медиаэстетики, проявляется прежде всего в оформлении символических элементов: рисунков и маркеров, которые должны формировать необходимое отношение адресата к информации. Выбор визуальных средств основан на ассоциативном принципе, что связано и с контекстным восприятием, о котором уже шла речь. Например, количество телевизоров в домах разных стран обозначено пультами (https://aif.ru/dontknows/infographics/v_domah_zhiteley_kakih _stran_bolshe_vsego_televizorov_infografika), что позволяет увидеть динамику потребления телеконтента и вспомнить советский мультфильм про 38 попугаев и разные способы измерения. Развлекательно-иронический образ дополняется фотоколлажем, в котором голова человека заменена телевизором. Уровень образования обозначается количеством прочитанных книг, (вполне в логике национальной традиции) в другой инфографике (https://aif.ru/society /education/kto_bystree_naydyot_rabotu_chelovek_s_diplomom_ili_bez).

А в инфографике о нефтепродуктах используются символические изображения их «потребителей», которые напоминают рисунки детских книг или учебников (https://aif.ru/money/economy/kakie_byvayut_vidy_nefteproduktov_infografika).

Другим визуальным средством диалогичности можно назвать цветовое оформление: привычное всем соотношение зеленый - разрешено, красный - запрещено используется в инфографиках о полезных и вредных для мозга продуктах (https://aif.ru/health/food/10_druzey_i_5_vragov_mozga_ot_kakih_bolezney_pomogaet_modna ya_dieta_mind), с «антипохмельными рецептами» (https://aif.ru/dontknows/infographics /kakie_blyuda_russkoy_kuhni_pomogut_ot_pohmelya), в инфоргафике-рекомендации о компосте (https://aif.ru/dacha/ogorod/chto_kladem_v_kompost); знакомые всем обозначения мальчика голубым цветом и девочки розовым цветом в тексте «Самые популярные и не- 
обычные детские имена» (https://aif.ru/society/people /samye_populyarnye_i_neobychnye _detskie_imena_infografika) и т. п. Отношение к информации может быть представлено и символическими изображениями: хорошо и плохо - это поднятый и опущенный большой палец (https://aif.ru /auto/roads/shlagbaum_ot _ponaehavshih_zakryt_dvor_ot_chuzhakov _stanet_proshche), зеленая галочка и красный крест (https://aif.ru/health/life/sygraem _v_yashchik_kak_smotret_televizor_bez_vreda_dlya_zdorovya); улыбающийся смайлик как символ хорошего настроения (https://aif.ru/health/life/vskrytie_mozga_dopingi _dlya_intellekta_razdelyat_lyudey_na_bogov_i_glupcov), красный круг с изображением как символ запрета (https://aif.ru/money /market/srok_ili_shtraf_tovary_kotorye_luchshe _ne_pokupat_i_ne_prodavat_v_seti) и т. п.

Как и лексические средства, цвет и изображение оказывают воздействие на адресата, вызывая определенные эмоции и формируя отношение к информации. Поэтому нередко диалогические средства в инфографике, как вербальные, так и невербальные, обладают и суггестивным эффектом: «Слово, даже изначально лишенное эстетической ценности, может обрести эстетическое значение, которое определяет его суггестивные возможности - способность вызывать эмоции, заражать определенным отношением к жизни; гедонистические - доставлять радость, приносить наслаждение; коммуникативные - открывать читателю новые возможности для диалога с окружающей его реальностью, с автором; эвристические способствовать открытию в изображаемой действительности нового, неизведанного» [Цветова, 2017]. Заметим, что в инфографике «АиФ» эти функции выполняют и дизайнерские элементы.

Как общественно-политическое издание «Аргументы и факты» освещает самые разные темы, поэтому в инфографике представлена информация:

- о политических событиях:

- «Военное присутствие США в странах Европы» (https://aif.ru/dontknows /infographics/voennoe_prisutstvie_ssha_v_stranah_mira_infografika), «Прописка не помеха» (http://www.aif.ru/politics/russia/propiska_ne_pomeha_na_vyborah_mozhno_progolosovat_v_u proshchyonnom_poryadke), «Страны, гражданство которых можно купить» (https://aif.ru/society/people/strany_v_kotoryh_mozhno_kupit_grazhdanstvo_infografika), «Кто с кем воюет в Сирии» https://aif.ru/dontknows/infographics/kto_s_kem_voyuet _v_sirii_storony_konflikta_v_infografike), «Кадры новые и старые» (https://aif.ru/politics/russia/kadry_novye_i_starye_kakim_budet_novoe_pravitelstvo);

- $O$ проблемах экономики: - «Доплаты за стаж и детей» (https://aif.ru/money/mymoney/kak_pensionerov_utkami_kormyat_pensionnye_sensacii_okazav shiesya_nepravdoy), «Деньги просто так» (https://aif.ru/money/economy/dengi_prosto _tak_mogut_li_u_nas_poyavitsya_bezuslovnye_vyplaty_grazhdanam), «Тарифы - к стенке!» (https://aif.ru/realty/utilities/tarify_k_stene_chto_teper_izmenitsya_v_rabote_upravlyayushchih _kompaniy);

- интересные факты истории:

«Самые знаменитые археологические находки в России» (https://aif.ru/society/history/samye_znamenitye_arheologicheskie_nahodki_v_rossii_infografika ), «Когда в Европе был исполнен последний смертный приговор» (https://aif.ru/society /history/kogda_v_evrope_byl_ispolnen_posledniy_smertnyy_prigovor_infografika), «Пулемет Максима» (https://aif.ru/society/army/pulemet_maksima_infografika);

- O ситуации в социальной сфере (наиболее популярное направление в инфографике):

- «Выплаты и компенсации семьям, взявшим на воспитание ребенка» (https://aif.ru/money/mymoney/zarplata_za_mnogodetnost_kak_stolica_pomogaet_semyam_s_d etmi), «Волонтеры и контролеры» (https://aif.ru/realty/city/volontyory_i_kontrolyory_kak _pouchastvovat_v_razvitii_moskvy), «Сколько стоит “коммуналка" в России и на Западе» (https://aif.ru/realty/utilities/ne_myt_posudu_spat_v_holode_skolko_stoit_kommunalka_v_rf_i_ 
na_zapade), «Комфортная среда» (https://aif.ru/realty/city/komfortnaya_sreda_kak _decentralizaciya_goroda_uluchshaet_usloviya_zhizni_lyudey);

- О спортивных и культурных событиях: «Расписание хоккейных матчей на Олимпиаде - 2018» (https://aif.ru/olymp2018/dontknows/raspisanie_hokkeynyh_matchey_na _olimpiyskih_igrah-2018_infografika), «Фестиваль “День России. Московское время”» (https://aif.ru/culture/freeway/festival_den_rossii_moskovskoe_vremya_infografika), «Выступление сборной России на ЧМ» (https://aif.ru/football2018/not_understand/vystuplenie_sbornoy _rossii_na_chm_v_cifrah_i_faktah), «Самые посещаемые художественные музеи мира» (https://aif.ru/culture/art/samye_poseshchaemye_hudozhestvennye_muzei_mira_infografika);

- Полезные советы (еще одно популярное направление): «Срок или штраф» (https://aif.ru/money/market/srok_ili_shtraf_tovary_kotorye_luchshe_ne_pokupat_i_ne_prodavat _v_seti), «Спорт вреден?» (https://aif.ru/health/life/sport_vreden_komu_i_pochemu protivopokazany_fizicheskie_nagruzki), «Календарь питания для Великого поста» (https://aif.ru/food/diet/kalendar_pitaniya_dlya_velikogo_posta_2018_goda), «Условия для выращивания рассады» (https://aif.ru/dacha/flowers/usloviya_dlya_vyrashchivaniya_rassady _odnoletnih_cvetov_infografika);

- Развлекательный контент: «Самые длинные кинофраншизы» (https://aif.ru/culture/movie/samye_dlinnye_kinofranshizy_infografika), «В каких странах не хватает женщин» (https://aif.ru/society/people/v_kakih_stranah_ne_hvataet_zhenshchin _infografika), «Что ценят в мужчинах и женщинах» (https://aif.ru/health /psychologic/chto_cenyat_v_muzhchinah_i_zhenshchinah).

Если говорить о тематическом своеобразии инфографики «АиФ», то прежде всего оно связано с формой подачи - соотношением вербальной и визуальной составляющих. Как правило, в публикациях о политике доминирует вербальная информация, и визуальный ряд часто содержит фотографии героев публикации, тогда как в большинстве других инфографик еженедельника используются схематичные рисунки.

Фотография в подавляющем большинстве проанализированных медиатекстов выполняет две функции: во-первых, персонализации («Волонтеры и контролеры» https://aif.ru/realty/city/volontyory_i_kontrolyory_kak_pouchastvovat_v_razvitii_moskvy) и эмоционального воздействия. Во втором случае она выполняет еще и роль композиционного центра, вокруг которого строится публицистический образ. Яркий пример - инфографика «Не городить барьеры. Какие возможности предоставляет столица инвалидам?» (https://aif.ru/realty/city/ne_gorodit_barery_kakie_vozmozhnosti_predostavlyaet_stolica_invalidam), большую часть которой занимает фотоиллюстрация, символизирующая тему публикации.

Общие принципы оформления, вне зависимости от темы инфографического текста, таковы: выделение в композиции фактического материала, представленного цифровыми значениями; единство цветового оформления - доминирование одного цвета и использование контрастных цветов для противопоставления (сравнения) данных; единообразие дизайнерских элементов - графические рисунки, значки-символы (от обычных стрелок и галочек до изображения кошелька, обозначающего денежную сумму, водопроводного крана, обозначающего коммунальные услуги, и инструментов, обозначающих ремонт, в инфографике «Не мыть посуду, спать в холодильнике» https:/aif.ru /realty/utilities/ne_myt_posudu_spat_v_holode_skolko_stoit_kommunalka_v_rf_i_na_zapade).

Такие особенности, как схематичность рисунков и символическая лапидарность изображений, отсутствие цветового и шрифтового разнообразия, обусловлена общими эстетическими принципами дизайна «Аргументов и фактов», то есть непосредственным контекстом, и культурными традициями - узнаваемостью предлагаемых авторами инфографики условных обозначений и изображений.

Еще одно общее правило дизайнерских решений в инфографике «АиФ» - это композиционная целостность, характеризующая разные форматы текста: графики, таймлинии, рейтинги, карты, диаграммы. В основе композиции может быть вертикальная или гори- 
зонтальная структура, в этом случае реципиенту предлагается сопоставить данные. Контрастный принцип поддерживается увеличением или уменьшением кегля шрифта, изменением его начертания, цветовым оформлением, дополнительными дизайнерскими эффектами. Так организовано пространство в инфографике «Меньше работают там, где больше зарабатывают» (https://aif.ru/money/business/rabotaem_mnogo_a_zarabatyvaem _pochemu_v_rossii_ne_rastut_zarplaty).

Другой принцип композиции - равномерное (круговое или вертикальногоризонтальное) размещение данных, он используется для представления информации, которая одинаково важна и требует постепенного восприятия. Например, в инфографике «Товары, которые лучше не покупать и не продавать» (https://aif.ru /money/market/srok_ili_shtraf_tovary_kotorye_luchshe_ne_pokupat_i_ne_prodavat_v_seti) roризонтально-вертикальная структура содержит символические обозначения запрещенных товаров и меру наказания. В центре композиции - фотоизображения, которые обозначают конкретный тип запрещенных товаров. Нижнюю часть инфографики занимают перечень законодательных актов и объяснение символов-знаков. В инфографике не используется подложка, чтобы исключить любой намек на рекреативную функцию и сконцентрировать внимание адресата на фактических данных. Дизайнеры используют два цвета - красный и черный. Семантика красного - опасность, запрет; черный (ключевой, основной) необходим для точного представления информации, не допускающей двоякого толкования.

По принципу заполнения всего пространства создана инфографика «Когда в Европе был исполнен последний смертный приговор» (https:/aif.ru/society/history/kogda_v _evrope_byl_ispolnen_posledniy_smertnyy_prigovor_infografika). Авторы выбирают форму карты и с помощью визуальных компонентов (насыщенность цвета, символическое обозначение вида казни) и вербальных компонентов (название стран и указание года) акцентируют внимание реципиента и создают цельный публицистический образ.

Доминирование условных обозначений и графических рисунков в публикациях «АиФ» объясняется, с одной стороны, общими принципами оформления газеты, а с другой стороны, стремлением авторов представить информацию максимально обобщенно. Так подчеркивается ее универсальность и прагматическая ценность для любого адресата. Рисунки не только выполняют дизайнерско-эстетическую функцию, но и участвуют в создании публицистического образа, реализуя, в значительной степени больше других элементов, воздействующую и коммуникативную функции. Так, в инфографике «Сколько леса в разных странах» (https://aif.ru/society/ecology/skolko_lesa_v_raznyh_stranah _mira_infografika) изображение улыбающегося туриста и доминирование зеленого цвета нацелены на создание образа леса как символа счастливой жизни страны и любого человека; теневое изображение женщины с коляской в инфографике «Демография в России: пошли на убыль» (https://aif.ru/society /people/demografiya_v_rossii_poshli_na_ubyl) является эмоциональной оценкой ухудшения демографической ситуации в стране. Можно говорить и об идеологической функции изобразительных элементов, которые формируют ценностное отношение к фактам, событиям, явлениям, персонам.

\section{Заключение}

Таким образом, исследование инфографики «АиФ» позволяет сделать вывод о том, что медиаэстетический эффект достигается прежде всего визуальными элементами (начертание шрифта, цвет, фотография, коллаж, иллюстрация, графика, диаграмма, маркеры), однако в создании этого эффекта участвует и вербальная составляющая (заголовок, цитаты, рекомендации). Выбор вербальных и визуальных средств зависит от объема данных, которые необходимо представить как цельный, завершенный, системно выстроенный и эстетически оформленный медиатекст. Поликодовый характер инфографики основан на доминировании визуальной составляющей, что в публикациях «АиФ» проявляется не 
только в способах представления иллюстраций (фотографий, рисунков, коллажей), но и в шрифтовом оформлении, и в цветовой гамме.

Особую роль играет композиция, участвующая в установлении контакта и диалога с адресатом, выражающая основную идею текста, в основе которой могут быть контраст, эволюция, сравнение, побуждение, развлечение. Как и большинство поликодовых текстов, инфографика характеризуется полифункциональностью: авторы не ограничиваются сообщением актуальной, социально значимой информации, объединяя разные знаковые системы, они реализуют воздействующую, коммуникативную, идеологическую, культуроформирующую функции, а в некоторых публикациях - и развлекательную. Общие принципы оформления обусловлены как общими дизайнерскими приемами еженедельника «Аргументы и факты», так и культурными традициями, что наиболее ярко выражено в визуальной составляющей, которая создает на основе ассоциативного ряда цельный публицистический образ.

\section{Список литературы}

1. Ворошилова М.Б. 2006. Креолизованный текст: аспекты изучения. Политическая лингвистика. Вып. 20: 180-189.

2. Выровцева Е.В., Симакова С.И. 2019. Инфографика как вид публицистического текста. Вестник Новосибирского государственного университета. Серия: История, филология, 18 (6): $104-$ 114. DOI 10.25205/1818-7919-2019-18-6-104-114.

3. Дускаева Л.Р. 2016. О жанровых текстовых категориях. Жанры речи, 2 (14): 25-32. DOI: https://doi.org /10.18500/2311-0740-2016-2-14-25-32.

4. Загидуллина М.В. 2017а. Медиаэстетика в аспекте эколингвистического подхода. В кн.: Język rosyjski XXI wieku. Źrodła i perspektywy. Русский язык XXI века. Истоки и перспективы. Под ред. G. Mańkowska и др. Варшава. Издательство: Instytut Rusycystyki Uniwersytetu Warszawskiego, 24-29.

1. Загидуллина М.В. 2017б. Эстетический компонент поликодовых медиатекстов. В кн. Медиалингвистика. Материалы II Международной научно-практической конференции «Язык в координатах массмедиа», г. Санкт-Петербург, 02-06 июля 2017 года. Под ред. А.А. Малышева. СПб., Институт «Высшая школа журналистики и массовых коммуникаций» СПГУ: 101-103.

2. Загидуллина М.В. 2019. Медиаэстетика и эстетика журналистики: К вопросу о разграничении феноменов. В кн.: Медиа в современном мире. 58-е Петербургские чтения. Коммуникации в медиаиндустрии: акторы, технологии, тренды. Сборник материалов круглого стола Междунарадного научного форума, г. Санкт-Петербург, 18-19 апреля 2019 года. В 2-х т. Т.1. Под ред. В.В. Васильевой. СПб., СПбГУ: 150-151.

3. Короченский А.П. 2019. Постжурналистика: сущность, признаки, социальные эффекты. Журнал Белорусского государственного университета. Журналистика. Педагогика, 1: 6-12.

4. Левшаков В.С. 2017. Роль субъекта в публицистическом диалоге. Вестник Воронежского государственного университета. Серия: Филология. Журналистика, 1: 129-131.

5. Симакова С.И. 2020. «Цивилизация глаза»: специфика визуальной репрезентации события. Гуманитарный вектор, 15, 1: 125-133. DOI: 10.21209/1996-7853-2020-15-1-125-133.

6. Симакова С.И., Распопова С.С., Выровцева Е.В. 2017. Визуальный поворот в массовых коммуникациях. Под ред. С.И. Симаковой. Челябинск, Изд-во Челябинского университета, 112 с.

7. Цветова Н.С. 2017. Медиатекст в свете практической эстетики. Медиалингвистика, 4(19): 18-26.

8. Cairo A. 2013. The functional art: An introduction to information graphics and visualization. Berkeley, $384 \mathrm{p}$.

9. Krotz F. 2007. The meta-process of 'mediatization' as a conceptual frame. Global Media and Communication, 3 (3): 256-260. DOI: 10.1177/17427665070030030103.

10. Manovich L. 2001. The language of new media. Cambridge, Massachusetts, London, England, The MIT Press, 354 p.

11. Mirzoeff N. 1998. What is visual culture? In: The Visual Culture Reader. Ed. N. Mirzoeff. London, New York: Routledge: 3-13.

12. Mitchell W. J. T. 2015. Image science: iconology, visual culture, and media aesthetics. The University of Chicago Press, 264 p. 
13. Luhmann N. 1987. Soziale Systeme: Grundriß einer allgemeinen Theorie. Suhrkamp Verlag, 675 p.

14. Simakova S., Panyukova S., Topchii I. 2019. Autonomy of Picture: The Place of Author's Drawings in Modern Communication of Scientific-Popular Theme. Przegląd Wschodnioeuropejski, 10 (1): 337-345. https://doi.org/10.31648/pw.4529

15. Simakova S., Topchii I. 2018. Media space visualization as a trend of modern era. SGEM International multidiscilinary scientific conference on social sciences and arts: conference proceedings. SGEM 2018. Volume 5: 205-213.

16. Topchii I. 2018. Comprehensive analysis of the mass media visual component in the aspect of media aesthetics. TEEM'18 Proceedings of the Sixth International Conference on Technological Ecosystems for Enhancing Multiculturality, Salamanca, Spain, October 24-26, 2018: 546-552. DOI: $10.1145 / 3284179.3284272$.

17. Topchii I. 2019. Theoretical aspects of the news media strategies and specificies within social networks. In: Journalistic text in a new technological environment: achievements and problems European Proceedings of Social and Behavioural Sciences (III Post mass media in the modern informational society (PMMIS 2019), Chelyabinsk State University, March 28-29, 2019, 66: 440-450. DOI: 10.15405/EPSBS.2019.08.02.51.

\section{References}

1. Voroshilova M.B. 2006. Kreolizovannyy tekst: aspekty izucheniya [Creolized Text: Learning Aspects]. Political Linguistics. Iss. 20: 180-189.

2. Vyrovtseva E.V., Simakova S.I. 2019. Infografika kak vid publitsisticheskogo teksta [Infographics as a type of publicistic text]. Novosibirsk State University Bulletin. Series: History and Philology, 18 (6): 104-114. DOI 10.25205/1818-7919-2019-18-6-104-114.

3. Duskaeva L.R. 2016. O zhanrovykh tekstovykh kategoriyakh [About genre text categories]. Speech Genres, 2 (14): 25-32. DOI: https://doi.org /10.18500/2311-0740-2016-2-14-25-32.

4. Zagidullina M.V. 2017a. Mediaestetika v aspekte ekolingvisticheskogo podkhoda [Media aesthetics in the aspect of the ecolinguistic approach]. In: Język rosyjski XXI wieku: Źródła i perspektywy. Russkiy yazyk KhKhI veka. Istoki i perspektivy [Język rosyjski XXI wieku: Źródła i perspektywy. Russkiy yazyk KhKhI veka. Istoki i perspektivy]. Eds. G. Mańkowska, M. Kuratczyk, D. MuszyńskaWolny, J. Wasiluk. Warszawa, Publ. Instytut Rusycystyki Uniwersytetu Warszawskiego: 24-29.

5. Zagidullina M.V. 2017b. Esteticheskiy komponent polikodovykh mediatekstov [The aesthetic component of polycode media texts]. In: Medialingvistika [Medialinguistics]. Proceedings of the II International scientific and practical conference "Language in Mac-smedia coordinates", Saint Petersburg, 02-06 July 2017. Ed. A.A. Malyshev. SPb., Publ. Institut «Vysshaya shkola zhurnalistiki i massovykh kommunikatsiy» SPGU: 101-103.

6. Zagidullina M.V. 2019. Mediaestetika i estetika zhurnalistiki: K voprosu o razgranichenii fenomenov [Media aesthetics and aesthetics of journalism: On the issue of distinguishing between phenomena]. In: Media v sovremennom mire. 58-e Peterburgskie chteniya [Media in the modern world. 58th Petersburg Readings]. Kommunikatsii v mediaindustrii: aktory, tekhnologii, trendy [Communication in the media industry: actors, technologies, trends.]. Collection of materials of the round table of the international Scientific forum, Saint Petersburg, April 18-19, 2019. In 2 volumes. Volume 1. Ed. V.V. Vasil'eva. SPb., Publ. SPbGU: 150-151.

7. Korochenskiy A.P. 2019. Postzhurnalistika: sushchnost', priznaki, sotsial'nye effekty [Postjournalism: essence, features, social effects]. Journal of the Belarusian State University. Journalism and Pedagogic, 1: 6-12.

8. Levshakov V.S. 2017. Rol' sub"ekta v publitsisticheskom dialoge [The role of the subject in the journalistic dialogue]. Proceedings of Voronezh State University. Series: Philology. Journalism, 1: 129-131.

9. Simakova S. I. 2020. «Tsivilizatsiya glaza»: spetsifika vizual'noĭ reprezentatsii sobytiya ["The civilization of the eye": the specificity of the visual representation of the event]. Humanitarian Vector, 15 (1): 125-133. DOI: 10.21209/1996-7853-2020-15-1-125-133.

10. Simakova S.I., Raspopova S.S., Vyrovtseva E.V. 2017. Vizual'nyy povorot v massovykh kommunikatsiyakh [Visual turn in mass communications]. Ed. S.I. Simakova. Chelyabinsk, Publ. Izd-vo Chelyabinskogo universiteta, $112 \mathrm{p}$. 
11. Tsvetova N. S. 2017. Mediatekst v svete prakticheskoy estetiki [Media text in the light of practical aesthetics]. Media Linguistics, 4 (19): 18-26.

12. Cairo A. 2013. The functional art: An introduction to information graphics and visualization. Berkeley, 384 p.

13. Krotz F. 2007. The meta-process of 'mediatization' as a conceptual frame. Global Media and Communication, 3 (3): 256-260. DOI: 10.1177/17427665070030030103.

14. Manovich L. 2001. The language of new media. Cambridge, Massachusetts, London, England, The MIT Press, $354 \mathrm{p}$.

15. Mirzoeff N. 1998. What is visual culture? In: The Visual Culture Reader. Ed. N. Mirzoeff. London, New York: Routledge: 3-13.

16. Mitchell W. J. T. 2015. Image science: iconology, visual culture, and media aesthetics. The University of Chicago Press, $264 \mathrm{p}$.

17. Luhmann N. 1987. Soziale Systeme: Grundriß einer allgemeinen Theorie. Suhrkamp Verlag, 675 p.

18. Simakova S., Panyukova S., Topchii I. 2019. Autonomy of Picture: The Place of Author's Drawings in Modern Communication of Scientific-Popular Theme. Przegląd Wschodnioeuropejski, 10 (1): 337-345. https://doi.org/10.31648/pw.4529

19. Simakova S., Topchii I. 2018. Media space visualization as a trend of modern era. W: SGEM International multidiscilinary scientific conference on social sciences and arts. Conference proceedings. SGEM 2018. Volume 5: 205-213.

20. Topchii I. 2018. Comprehensive analysis of the mass media visual component in the aspect of media aesthetics. TEEM'18 Proceedings of the Sixth International Conference on Technological Ecosystems for Enhancing Multiculturality, Salamanca, Spain, October 24-26, 2018: 546-552. DOI: $10.1145 / 3284179.3284272$.

21. Topchii I. 2019. Theoretical aspects of the news media strategies and specificies within social networks. In: Journalistic text in a new technological environment: achievements and problems European Proceedings of Social and Behavioural Sciences (III Post mass media in the modern informational society (PMMIS 2019), Chelyabinsk State University, March 28-29, 2019, 66: 440-450. DOI: 10.15405/EPSBS.2019.08.02.51.

\section{ИНФОРМАЦИЯ ОБ АВТОРЕ}

Симакова Светлана Ивановна, кандидат филологических наук, доцент, заведующая кафедрой журналистики и массовых коммуникаций факультета журналистики Челябинского государственного университета,

г. Челябинск, Россия

\section{INFORMATION ABOUT THE AUTHOR}

Svetlana I. Simakova, Candidate of Philology, Associate Professor, Head of the Department of Journalism and Mass Communications of the Faculty of Journalism, Chelyabinsk State University, Chelyabinsk, Russia 